\title{
IAMSE Awards 2020
}

Published online: 13 November 2020

(C) International Association of Medical Science Educators 2020

\section{Distinguished Career Award for Excellence in Teaching and Educational Scholarship \\ The Distinguished Career Award for Excellence in Teaching and Educational Scholarship recognizes an IAMSE member who has a distinguished record of educational scholarship, including educational research and dissemination of scholarly approaches to teaching and education. Candidates should be Professor, Associate Professor, or equivalent rank, or have demonstrated greater than 10 years of educational scholarship. Additionally, candidates must have a significant record of engagement within IAMSE.}

2020 Distinguished Career Award Winner: Dr Carol Nichols Medical College of Georgia at Augusta University, USA

Early Career Award for Excellence in Teaching and Innovation

The Early Career Award for Excellence in Teaching and Innovation honors an IAMSE member who has made significant innovations to the field in the short time they have focused their careers toward enhancing teaching, learning and assessment. Candidates for this award will be Assistant Professor or equivalent rank, or have demonstrated less than 10 years of educational scholarship.

2020 Early Career Award Winner: Dr Amber Heck TCU and UNTHSC School of Medicine, USA

Edward Patrick Finnerty Lifetime Achievement Award

This award is bestowed upon an individual member who has demonstrated a sustained involvement in and commitment to the advancement of the International Association of Medical Science Educators through their many types of service to the organization at the highest levels of performance. The special nature of this award makes it one for which a member may not apply, but rather, it represents the highest level of recognition that the organization, through selection by its Board of Directors, can provide to a most worthy individual whose work on behalf of IAMSE has shown a consistent history of distinguished accomplishments.

2020 Finnerty Award Winner-Dr Giulia Bonaminio, PhD University of Kansas School of Medicine, USA
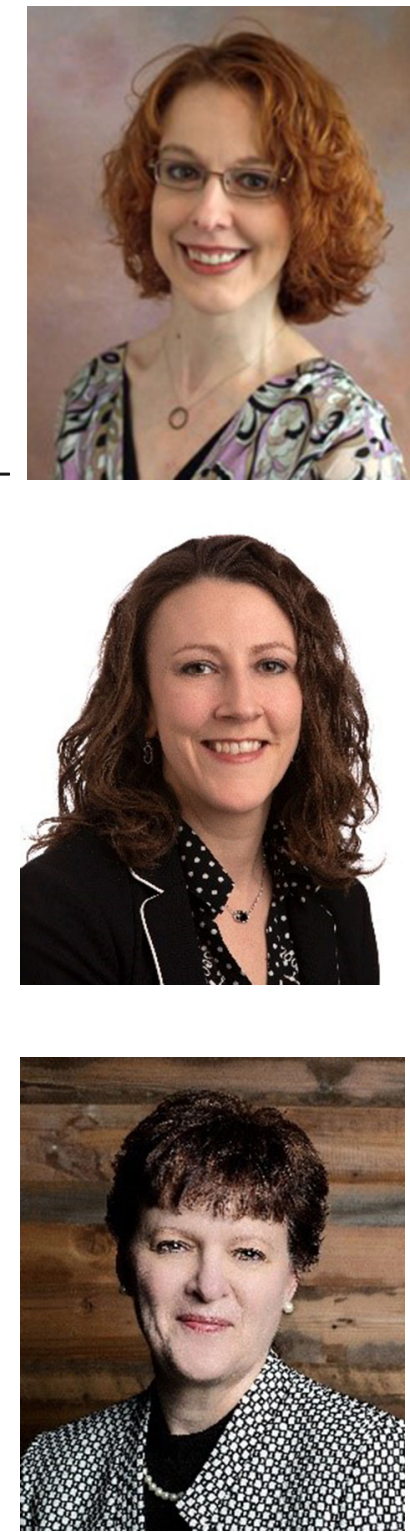

Publisher's Note Springer Nature remains neutral with regard to jurisdictional claims in published maps and institutional affiliations. 